Check for updates

Cite this: RSC Adv., 2018, 8, 4561

Received 27th October 2017

Accepted 29th December 2017

DOI: $10.1039 / c 7 r a 11866 j$

rsc.li/rsc-advances

\section{Novel approaches to immobilize Candida rugosa lipase on nanocomposite membranes prepared by covalent attachment of magnetic nanoparticles on poly acrylonitrile membrane}

\author{
Marzieh Aghababaie, (D) a Masoud Beheshti, ${ }^{\text {*b }}$ Abdol-Khalegh Bordbar (D) ${ }^{c}$ \\ and Amir Razmjou ${ }^{a}$
}

\begin{abstract}
Novel methods have been developed for lipase immobilization on poly acrylonitrile (PAN) membranes to increase the activity and stability of the immobilized lipase. In this study, poly acrylonitrile (PAN) membranes were aminated and then activated by glutaraldehyde or epichlorohydrine to be used for enzyme immobilization. In the other approach, magnetic nanoparticles (MNPs) which were functionalized with trichlorotriazine (TCT) or glutaraldehyde (GA) were attached to the membrane surface to prepare the nanocomposite membranes named TCT-MNPAPAN \& GA-MNPQPAN membranes. Candida rugosa lipase (CRL) was covalently immobilized on this activated nanocomposite membrane. Nanoparticles and nanocomposite membranes were characterized with various techniques such as SEM, TEM, XRD, FTIR, FTIR-ATR, AFM, contact angle goniometry and surface free energy measurement. The evidence of immobilization was also done by FTIR-ATR, enzyme activity, and loading efficiency. It was found that the activity of immobilized lipase on GA and TCT functionalized NCPAN membrane were about $50 \%$ and $31 \%$ higher than that immobilized on GA-activated PAN membrane. The kinetic parameters of enzymatic membranes showed the better conformation of the lipase enzyme immobilized on the TCT-MNP@PAN membrane. The presented enzymatic nanocomposite membranes are easy to prepare with low cost and are good candidates for use in membrane bioreactors.
\end{abstract}

\section{Introduction}

Efficient enzyme immobilization on easy handling supports which can be used in bioreactors and biosensors is an interesting issue, nowadays. Lipases (EC 3.1.1.3) are biocatalysts for many reactions such as esterification, transesterification, oil hydrolysis, polymer synthesis, and biodiesel production. ${ }^{1}$ Candida rugosa lipase (CRL) is one of the most favorable lipases which is widely used in many industries due to its low cost and high activity. ${ }^{2-4}$ Although, for the application of enzymes in industry, immobilization of enzymes improves the stability of enzyme, providing easy biocatalyst recycling and easier product purification, elongating their life span. ${ }^{1,5,6}$ One of the favorable supports for this goal is membranes which in some cases can facilitate the use of enzymes in membrane bioreactors, enzymatic reactors and biosensors and also can act as a separation unit. $^{7}$ Different membrane materials have been applied for

${ }^{a}$ Biotechnology Department, Faculty of Advanced Sciences and Technologies, University of Isfahan, Isfahan, Iran

${ }^{b}$ Chemical Engineering Department, University of Isfahan, Isfahan, Iran. E-mail: masbeh@yahoo.com; Tel: +983137934529

${ }^{c}$ Department of Chemistry, University of Isfahan, Isfahan, 81746-73441, Iran lipase immobilization. ${ }^{\mathbf{5 , 8 - 1 4}}$ In most reported cases, lipases have been physically immobilized on the membrane with the disadvantage of weak physical interactions. This reduces the reusability of the immobilized enzyme as a general feature of physical adsorption phenomena. However, direct covalent attachment of enzyme on the surface of the membrane, is more attractive while it would increase the stability and reusability of lipase. Although, immobilization of lipase on hydrophobic surfaces might improve lipase activity by rearranging their conformational structure (termed as 'lid') to open the active site. ${ }^{12}$ However, hydrophobic material has a negative effect on enzyme activity by denaturing the enzyme or by hampering the enzyme interaction with water-soluble substrates. ${ }^{15}$ Therefore, hydrophilic surfaces are more common to provide proper contact between enzyme and substrates. In this way, membrane with immobilized enzyme should have a moderate hydrophilic properties. ${ }^{12}$ Poly acrylonitrile (PAN) membrane is a hydrophilic membrane which is superior to many conventional membranes because of its reactive groups on the surface of membrane. ${ }^{\mathbf{1 6}}$ The aim of this study is to immobilize lipase on the PAN membrane in hydrated microenvironment along with increasing the enzyme activity. Recently, enzyme immobilization on nanocomposite membranes has been performed due to 
the combination of the benefits of membrane filtration system and nanoparticle including larger surface area, high stability and flexibility. ${ }^{17}$ In most of the studies, nanoparticles have been presented in the membrane by blending and coating technique. ${ }^{18-20}$ Nanocomposite membranes with different nanoparticles such as $\mathrm{TiO}_{2},{ }^{21} \mathrm{Al}_{2} \mathrm{O}_{3},{ }^{22} \mathrm{Fe}_{3} \mathrm{O}_{4},{ }^{18-20} \mathrm{SiO}_{2},{ }^{23} \mathrm{Ag}^{24}$ and mesoporous carbon nanoparticles ${ }^{25}$ have been applied for different purposes. Silica coated magnetic nanoparticles $\left(\mathrm{Fe}_{3}{ }^{-}\right.$ $\mathrm{O}_{4} @ \mathrm{SiO}_{2} \mathrm{NPs}$ ) have gained interests as enzyme carrier, due to their high surface area, high stability, and easy modification. ${ }^{26-28}$ The $\mathrm{Fe}_{3} \mathrm{O}_{4} @ \mathrm{SiO}_{2}$ NPs can be aminated using amino propyltriethoxysilane (APTS) and then be modified using glutaraldehyde ${ }^{29}$ or trichlorotriazine (TCT). ${ }^{27}$ These activated magnetic nanoparticles can be use for lipase immobilization with enhanced stability and activity. ${ }^{27}$

In our previous study, we immobilized lipase on $\mathrm{Fe}_{3} \mathrm{O}_{4} @ \mathrm{SiO}_{2}$ dip-coated membrane. ${ }^{30}$ Dip-coating method along with low hydrothermal process was applied in this study which was timeconsuming and difficult to be done for large membranes. ${ }^{30}$ Here, a novel activated and nanocomposite membranes were designed and prepared for covalent lipase immobilization. Two different approaches have been designed to immobilize lipase on PAN membrane. First, PAN membrane were amino functionalized and then were activated by glutaraldehyde (GA) or epichlorohydrine (EPI). CRL was immobilized on these heterofunctional supports which have several functionalities on their surfaces. $^{31}$

On the other approach, nanocomposite membranes were prepared by covalent attachment of magnetic nanoparticles (MNPs), which was functionalized with GA or trichlorotriazine (TCT), on the membrane surface. To the knowledge of the authors of this work, there are no study regarding the preparation of nanocomposite membrane by covalent attachment of nanoparticles on the surface of membrane and also there is no study in the case of lipase immobilization on polyacrylonitrile membrane.

In this way, hydrophilic properties of the membranes and lipase microenvironment are different which can effect the activity of CRL. The membranes were characterized by various techniques such as SEM, TEM, XRD, FTIR, FTIR-ATR, AFM, contact angle goniometry and surface free energy measurement. Subsequently, CRL was covalently immobilized on these membranes and evidence of immobilization was done by FTIRATR, enzyme activity and loading efficiency.

\section{Experimental}

\section{Materials}

Poly acrylonitrile (PAN) ultrafiltration (UF) membrane was purchased from Sterlitech. Lipase from Candida rugosa (lyophilized powder, Type VII, nominal activity $\gg 700 \mathrm{U} \mathrm{mg}^{-1}$ ), Bovine Serum Albumin (BSA), para-nitrophenyl palmitate ( $p$ NPP), Coomassie Brilliant Blue G-250, and amino propyltriethoxysilane (APTS) were purchased from Sigma Chemical Co. (St. Louis, MO, USA). The iron(III) chloride hexahydrate $\left(\mathrm{FeCl}_{3} \cdot 6 \mathrm{H}_{2} \mathrm{O}, 99.0 \%\right)$, iron(II) chloride tetrahydrate $\left(\mathrm{FeCl}_{2} \cdot 4 \mathrm{H}_{2}\right.$ O, 99.7\%), Triton X-100, isopropyl alcohol (99.7\%) and Arabic gum were provided from Daejung Chemicals. Tetraethyl orthosilicate (TEOS), ammonia $\left(\mathrm{NH}_{3} \cdot \mathrm{H}_{2} \mathrm{O}, 25 \mathrm{wt} \%\right)$, glutaraldehyde (50\%), 1, 3, 5, trichlorotriazine (TCT) (cyanuric chloride) $(>99 \%)$, epichlorohydrin (>99\%), and tetrahydrofuran (THF) (99\%) were obtained from Merck. Methanol (99.7\%) and absolute ethanol were obtained from Carlo ERBA (99.9\%). All other chemicals were of analytical grade and used without purifications.

\section{Magnetic nanoparticle preparation}

Magnetic nanoparticles (MNPs) were synthesized by coprecipitation method and silica coated by sol-gel method as described previously. ${ }^{27,30,32}$ Briefly, the aqueous solution of $\mathrm{FeCl}_{3}$ and $\mathrm{FeCl}_{2}$ were mixed at a ratio of $2: 1$ in deionized water and stirred vigorously under a nitrogen atmosphere at $60{ }^{\circ} \mathrm{C}$. Magnetic nanoparticles (MNPs) was produced by the addition of $6 \mathrm{~mL}$ of $25 \%$ ammonia. The MNPs was washed several times with deionized water and ethanol. The obtained MNPs were redispersed in $200 \mathrm{~mL}$ ethanol and after vigorous stirring under nitrogen atmosphere $30 \mathrm{~mL}$ of deionized water, $15 \mathrm{~mL}$ of $\mathrm{NH}_{4} \mathrm{OH}$ and TEOS $(2 \mathrm{~mL})$ were added to the solution and stirred and sonicated for 5 hours. Afterward, silica coated MNPs $\left(\mathrm{Fe}_{3}-\right.$ $\mathrm{O}_{4} @ \mathrm{SiO}_{2} \mathrm{NPs}$ ) were washed with ethanol and water and dried at room temperature.

Silica-coated MNPs were dispersed in absolute ethanol and then APTS $(20 \%(\mathrm{v} / \mathrm{v}))$ was added and sonicated at $50{ }^{\circ} \mathrm{C}$ for 2 hours. The obtained aminated MNPs $\left(\mathrm{Fe}_{3} \mathrm{O}_{4} @ \mathrm{SiO}_{2} @ A P T S\right.$ NPs$)$ were washed with ethanol and distilled water, and then, dried at $40{ }^{\circ} \mathrm{C}$ oven to be used for further modifications.

The aminated MNPs were dispersed in THF and reacted with TCT $\left(20 \mathrm{mg} \mathrm{mL}^{-1}\right.$ ). The obtained TCT functionalized MNPs ( $\mathrm{Fe}_{3} \mathrm{O}_{4} @ \mathrm{SiO}_{2} @ A P T S @ T C T$ NPs) were washed with THF, ethanol, and water and then dried $40{ }^{\circ} \mathrm{C}$ oven.

In the other approach, the aminated MNPs were activated with $2 \%(\mathrm{v} / \mathrm{v})$ glutaraldehyde in phosphate buffer solution (PBS) (50 mM; pH = 7.5). The obtained GA functionalized MNPs $\left(\mathrm{Fe}_{3} \mathrm{O}_{4} @ \mathrm{SiO}_{2} @ A P T S @ G A\right.$ NPs) were washed with PBS and DI water and then dried in a $40{ }^{\circ} \mathrm{C}$ oven.

\section{Modification of the surface of PAN membrane}

The outer surface of PAN membrane was hydrolyzed and aminated in an aqueous solution containing $1 \mathrm{~N} \mathrm{NaOH}$ and $1 \mathrm{~N} 1,3-$ propanediamine at $60{ }^{\circ} \mathrm{C}$ for $20 \mathrm{~min}$ as shown in the below equation: ${ }^{33}$

$$
\begin{aligned}
& \mathrm{PAN}-\mathrm{CN}+\mathrm{H}_{2} \mathrm{~N}\left(\mathrm{CH}_{2}\right)_{3} \mathrm{NH}_{2}+\mathrm{H}_{2} \mathrm{O} \rightarrow \\
& \text { PAN-CONH}-\left(\mathrm{CH}_{2}\right)_{3}-\mathrm{NH}_{2}+\mathrm{NH}_{3}
\end{aligned}
$$

The resulting membranes were thoroughly rinsed with $\mathrm{pH} 7$ buffer and DI water. In this regards, four different activated membranes were prepared for further lipase immobilization. Modified membranes were activated by glutaraldehyde (GA) solution $(1 \% \mathrm{v} / \mathrm{v})$ in PBS $(50 \mathrm{mM}, \mathrm{pH}=7.5)$ at $25{ }^{\circ} \mathrm{C}$ for $2 \mathrm{~h}$ or epichlorohydrine (EPI) solution (5 mL of EPI solution and $10 \mathrm{~mL}$ of $1.5 \mathrm{M}$ sodium hydroxide) at $25{ }^{\circ} \mathrm{C}$ for $12 \mathrm{~h}$. Furthermore, nanocomposite membranes (NCM) were prepared by 
immersing the aminated PAN membranes in a solution of TCT or GA functionalized MNPs $\left(1 \mathrm{mg} \mathrm{mL}^{-1}\right.$; in DI water) to obtain TCT-MNP@PAN and GA-MNP@PAN membranes, respectively.

\section{Nanoparticles and nanocomposite membrane characterization}

The size and structure of magnetic nanoparticles were determined using a field emission scanning electron microscope (FESEM) (JEOL 7001F FEG), at $15 \mathrm{kV}$ acceleration voltages. To determine the size and morphology of $\mathrm{Fe}_{3} \mathrm{O}_{4} @ \mathrm{SiO}_{2}$ NPs transmission electron microscopy (TEM, Philips CM30, operating at $200 \mathrm{kV}$ ) were used. Functional groupings of the nanoparticles were determined by Fourier transform infrared (FTIR) spectroscopy using an FTIR spectrometer (JASCO FT/IR-6300, Japan). In order to investigate the functional grouping of the PAN membranes, modified membranes, nanocomposite membranes and enzymatic nanocomposite membranes, FTIRATR (FTIR with ATR (attenuated total reflectance) accessory) was used. Bruker D8-advance X-ray diffractometer with $\mathrm{Cu} \mathrm{K} \alpha$ radiation was used to investigated the $\mathrm{X}$-ray powder diffraction (XRD) spectra of $\mathrm{Fe}_{3} \mathrm{O}_{4} @ \mathrm{SiO}_{2} \mathrm{NPs}$.

The morphology of the nanocomposite membrane and existence of $\mathrm{Fe}_{3} \mathrm{O}_{4} @ \mathrm{SiO}_{2}$ NPs on the membrane surface was observed using SEM (environmental scanning electron microscope, Philips, XL30) and EDX (Energy dispersion of X-ray, Philips, XL30).

The roughness and surface morphology of the membranes were determined by atomic force microscopy (Scanning probe microscopy (SPM/DME) Dualscope C-26). The samples were cut into pieces of $3 \mathrm{~cm} \times 3 \mathrm{~cm}$ and different parts of each sample were scanned in tapping mode at $5 \mu \mathrm{m} \times 5 \mu \mathrm{m}$ and $2 \mu \mathrm{m} \times 2$ $\mu \mathrm{m}$. The average roughness was determined in the area of $2 \mu \mathrm{m}$ $\times 2 \mu \mathrm{m}$.

In order to investigate the hydrophilicity of the membrane surfaces, the contact angles formed by water droplets on the membrane surface were measured using goniometer method (average of at least 5 measurements). The surface free energy of membranes was obtained using acid-base (Van-Oss) with contact angles of three liquids of water, glycerol, and formamide with known parameters. ${ }^{11,34}$

\section{Enzyme immobilization}

The prepared membranes were cut in the dimension of $1 \mathrm{~cm} \times$ $1 \mathrm{~cm}$ and then immersed in lipase solution $(0.2-1.8 \mathrm{mg}$ in $1 \mathrm{~mL}$ of PBS; $50 \mathrm{mM}, \mathrm{pH} 7.5$ ) for 2 hours at shaker incubator at $25^{\circ} \mathrm{C}$ and then they were washed with PBS. Bradford method was used to estimate the amounts of lipase in the enzyme solution before and after immobilization. ${ }^{35}$ Immobilization efficiency was determined by the following equation:

$$
\text { Immobilization efficiency } \%=\left(C_{1} V_{1}-C_{2} V_{2}\right) \times 100 /\left(C_{1} V_{1}\right)
$$

where, $C_{1}, C_{2}, V_{1}$, and $V_{2}$ are the initial and final enzyme concentration, and volume of the enzyme solution used for immobilization and the supernatant after immobilization, respectively.

\section{Activity assay}

The hydrolysis of $p$-NPP as a substrate used to estimate the activities of free and immobilized lipases as it is reported previously. ${ }^{30}$ Briefly, a substrate solution which was a mixture of 9 volumes of solution B ( $0.4 \mathrm{~mL}$ of Triton X-100 and $0.1 \mathrm{~g}$ Arabic gum in $90 \mathrm{~mL}$ PBS; $50 \mathrm{mM}, \mathrm{pH} 7.5$ ) and 1 volume of solution $\mathrm{A}$ (30 mg $p$-NPP in $10 \mathrm{~mL}$ isopropanol) was prepared. The reaction would take place at $37^{\circ} \mathrm{C}$ by preincubating the substrate solution. For each activity assay, $1.8 \mathrm{~mL}$ of substrate solution and a specific amount of lipase or piece of membrane reacted for 2 minutes and released $p$-nitrophenol was measured at $405 \mathrm{~nm}$ in a UV/VIS spectrophotometer (Eppendorf) against the blank sample, which contains no enzyme. One unit of lipase activity $(1 \mathrm{U})$ is defined as the amount of enzyme or biocatalyst, which liberates 1 $\mu \mathrm{mol}$ of $p$-nitrophenol per minute under the assay condition. Lipase activity and specific activity were determined as follows:

Activity $\left(\mathrm{U} \mathrm{cm}^{-2}\right)=$

(activity of immobilized enzyme/surface area of membrane)

Specific activity $\left(\mathrm{U} \mathrm{mg}^{-1}\right.$ enzyme $)=($ lipase activity/ loading capacity)

Relative activity was defined as the percentage of the maximum activity obtained in that series.

\section{Kinetic parameters}

Michaelis-Menten kinetics was used to describe the dependence of enzyme activity on substrate concentration. The kinetic parameters $\left(K_{\mathrm{m}}\right.$ and $\left.v_{\max }\right)$ of free and immobilized lipase were determined in the concentration range of $0.1-0.5 \mathrm{mM}$ pNPP using Lineweaver-Burk equation as follows:

$$
1 / v=\left(1 / v_{\max }\right)+\left(K_{\mathrm{m}} / v_{\max }[\mathrm{S}]\right)
$$

where $v, v_{\max }, K_{\mathrm{m}}$ and [S] are specific velocity, maximum specific velocity, Michaelis-Menten constant and substrate ( $p$-NPP) concentration, respectively.

\section{Storage stability of immobilized lipase}

Storage stability of immobilized enzyme on TCT-MNP@PAN membranes were evaluated at room temperature for two weeks. In this way, membranes with immobilized enzyme were dried and maintained at capped glass bottle and some of them were maintained at buffer solution.

\section{Results and discussion}

\section{Characterization of nanoparticles}

According to the SEM and TEM of MNPs and $\mathrm{Fe}_{3} \mathrm{O}_{4} @ \mathrm{SiO}_{2} \mathrm{NPs}$ (Fig. 1(a) and (b)), respectively, the average size of $\mathrm{Fe}_{3} \mathrm{O}_{4} @ \mathrm{SiO}_{2}$ NPs is about $30 \mathrm{~nm}$ and has not been considerably changed due to silica coating. Fig. 1(c) shows the XRD spectrum of $\mathrm{Fe}_{3} \mathrm{O}_{4}$ @$\mathrm{SiO}_{2}$ NPs. In this spectrum, a broad peak around $2 \theta$ of $20-30^{\circ}$ shows the amorphous phase of $\mathrm{SiO}_{2}$, and the $2 \theta$ peaks at 35.05 , $41.65,50.05,67.37$, and 74.25 are the characteristic diffraction 

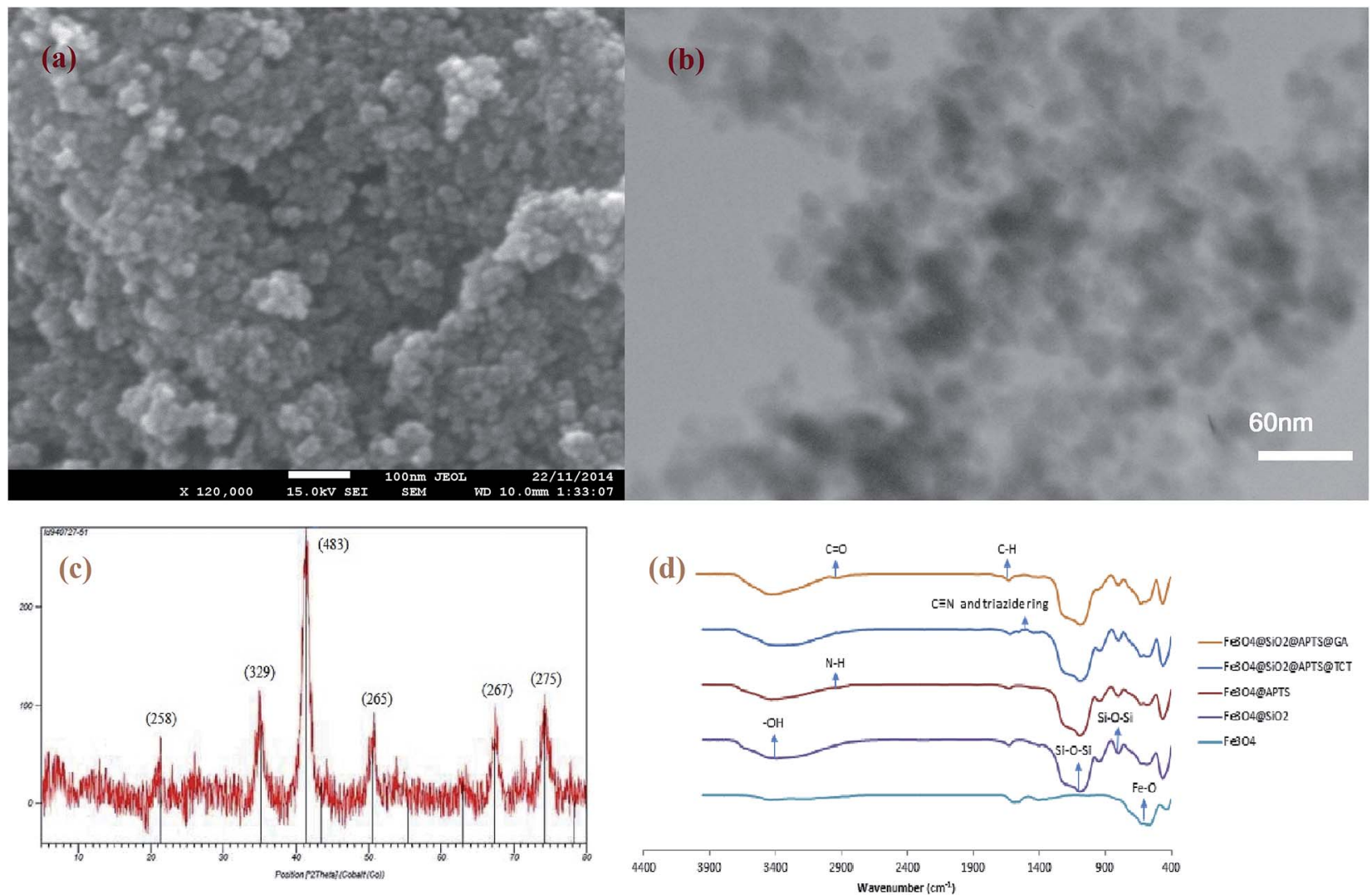

Fig. 1 (a) SEM analysis of MNP (b) TEM of $\mathrm{Fe}_{3} \mathrm{O}_{4} \mathrm{aSiO}_{2} \mathrm{NPs}$ (c) XRD pattern of $\mathrm{Fe}_{3} \mathrm{O}_{4} \mathrm{CSiO}_{2} \mathrm{NPs}_{\text {(d) }}{\mathrm{FTIR} \mathrm{spectra} \mathrm{of} \mathrm{Fe}_{3} \mathrm{O}_{4}, \mathrm{Fe}_{3} \mathrm{O}_{4} \mathrm{aSiO}}_{2}$, $\mathrm{Fe}_{3}-$ $\mathrm{O}_{4} @ \mathrm{SSiO}_{2} @ A P T S, \mathrm{Fe}_{3} \mathrm{O}_{4} @ \mathrm{CSiO}_{2} @ A P T S @ T C T$, and $\mathrm{Fe}_{3} \mathrm{O}_{4} @ \mathrm{CSiO}_{2} @ A P T S @ G A N P$.

of face centered cubic ( $\mathrm{fcc}$ ) of $\mathrm{Fe}_{3} \mathrm{O}_{4}$. The chemical composition of synthetized and modified MNPs were characterized by FTIR (Fig. 1(d)). In the spectra of $\mathrm{Fe}_{3} \mathrm{O}_{4}$ nanoparticles, the peak at $567 \mathrm{~cm}^{-1}$ corresponds to the $\mathrm{Fe}-\mathrm{O}$ bond. According to the spectra of $\mathrm{Fe}_{3} \mathrm{O}_{4} @ \mathrm{SiO}_{2} \mathrm{NPs}$, the peaks at 1091 and $797 \mathrm{~cm}^{-1}$ are referred to the asymmetric and symmetric stretching vibration of $\mathrm{Si}-\mathrm{O}-\mathrm{Si}$ bonds in an oxygen-silica tetrahedron, respectively. ${ }^{36,37}$ The peak at $3401 \mathrm{~cm}^{-1}$ in the spectra of $\mathrm{Fe}_{3} \mathrm{O}_{4} @ \mathrm{SiO}_{2}$ MNPs, corresponds to the $-\mathrm{OH}$ stretching vibration bond. After the salinization of silica coated MNPs with APTS, the peak at around $2923.5 \mathrm{~cm}^{-1}$ are representing the $\mathrm{C}-\mathrm{H}$ stretching vibration of APTS. However, the broad band at $3450 \mathrm{~cm}^{-1}$, which indicate the $\mathrm{N}-\mathrm{H}$ stretching vibration, is overlapped with $-\mathrm{OH}$ bond. In the spectra of functionalized MNPs with TCT ( $\mathrm{Fe}_{3} \mathrm{O}_{4} @ \mathrm{SiO}_{2} @ A P T S @ T C T$ NPs), the fine peaks between 1000 and $1600 \mathrm{~cm}^{-1}$ were presented the $\mathrm{C} \equiv \mathrm{N}$ and triazide ring and attachment of TCT to MNP. ${ }^{38}$ In the spectra of functionalized MNPS with GA $\left(\mathrm{Fe}_{3} \mathrm{O}_{4} @ \mathrm{SiO}_{2} @ A P T S @ G A N P s\right)$, the peak at 2900 stands for the $\mathrm{C}-\mathrm{H}$ stretching vibration of GA. Furthermore, in this spectra, the peak at 1710 is referred to the $\mathrm{C}=\mathrm{O}$ stretching bond of aldehyde group. After lipase immobilization, a peak at around 3430 and $1630 \mathrm{~cm}^{-1}$ were referred to amid group.

\section{Membrane characterization}

SEM and EDX. According to the SEM images (Fig. 2) of PAN membrane, as control, and nanocomposite PAN membrane
(NCPAN membrane) with TCT functionalized MNPs (TCTMNP@PAN membrane), the existence of magnetic nanoparticles on the membrane is evident. According to Fig. 2(b), the average size of TCT functionalized MNPs was determined to be $40 \mathrm{~nm}$ that was in accordance with the result of SEM and TEM of MNPs. EDX analysis of TCT-MNP@PAN membrane is shown in Fig. 2(c) and confirmed the presence of MNPs on this nanocomposite membrane. The peak at $1.8 \mathrm{keV}$ belonged to silica and the peak at $6.4 \mathrm{keV}$ belonged to Fe.

\section{(FTIR-ATR) of membranes}

ATR of control PAN and aminated PAN membranes are shown in Fig. 3(a). A sharp band at 2242 represents a stretching vibration of $\mathrm{C} \equiv \mathrm{N}$ band which can be seen in all the spectrums. A broad peak at about 3000-3300 in the spectra of aminated PAN is referred to $\mathrm{N}-\mathrm{H}$ stretching vibration of the primary amine group. The peak at 2900 in the spectra of aminated PAN refers to the $\mathrm{C}-\mathrm{H}$ stretching vibration of propyl group of diaminopropane. ATR of membranes which are activated by GA and EPI and enzymatic membranes are presented in Fig. 3(b). The peak at 2900 in the spectra of GA@PAN membrane represents the $\mathrm{C}-\mathrm{H}$ stretching vibration of glutaraldehyde. The presence of epoxy group on EPI@PAN membranes can be identified by the change in peaks at around 1250, 815-950 and $700 .^{39}$ However, some other peaks are observed in the spectra EPI@PAN which must be due to the crosslinking of epoxides, 


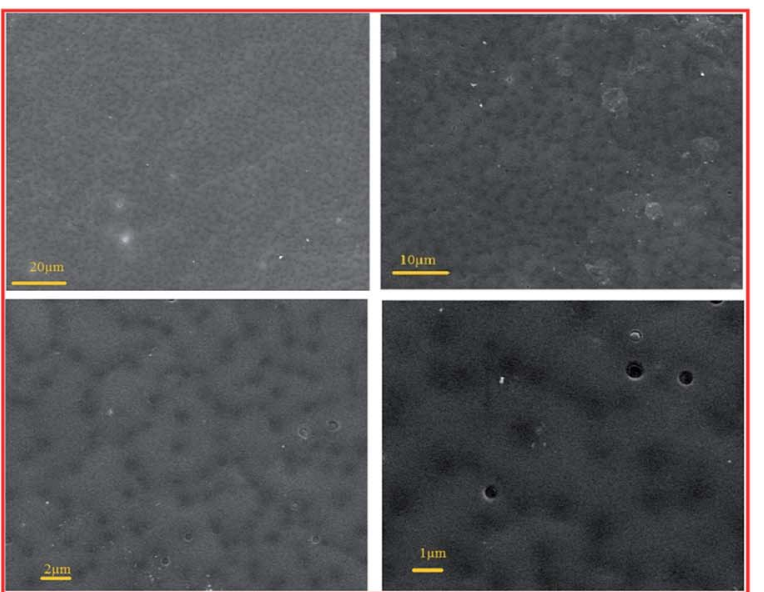

(a)

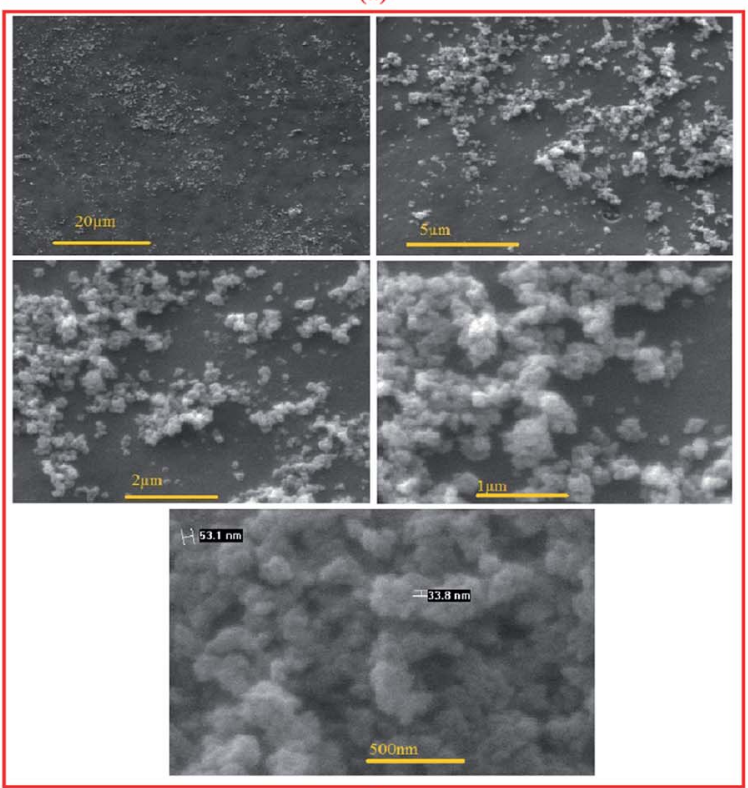

(b)

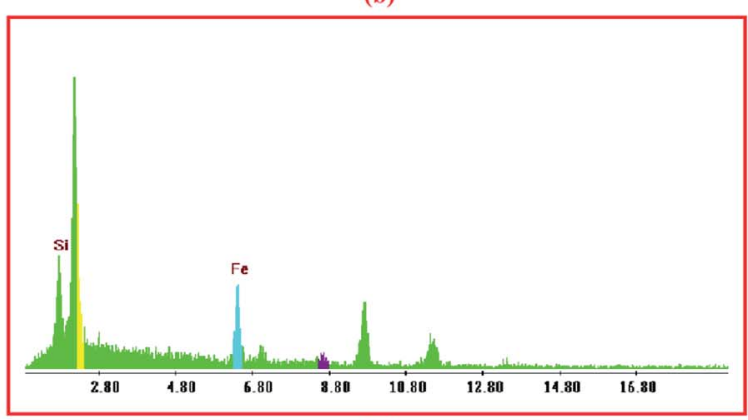

(c)

Fig. 2 SEM images of the surface of (a) PAN membrane and (b) TCTMNP(aPAN membrane (c) EDX spectrum of NCM.

intramolecular cyclization, or epoxy ring opening which lead to the formation of different types of products. ${ }^{39}$

After immobilization of CRL, a peak at around 3430 and $1630 \mathrm{~cm}^{-1}$ were assigned to amid group. GA-MNP@PAN membrane TCT-MNP@PAN membrane and ENZ@TCTMNP@PAN membrane are shown in Fig. 3(c). The peak at around 2900 in the spectra of GA-MNP@PAN membrane

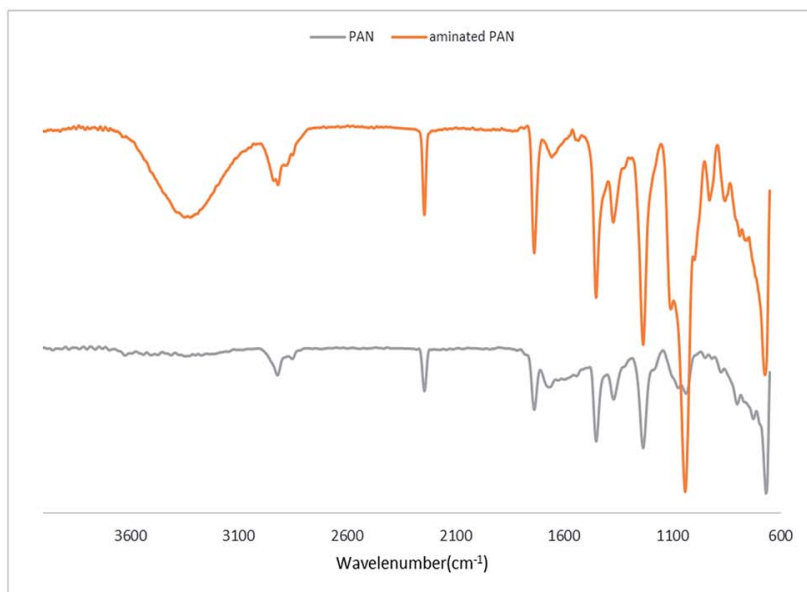

(a)

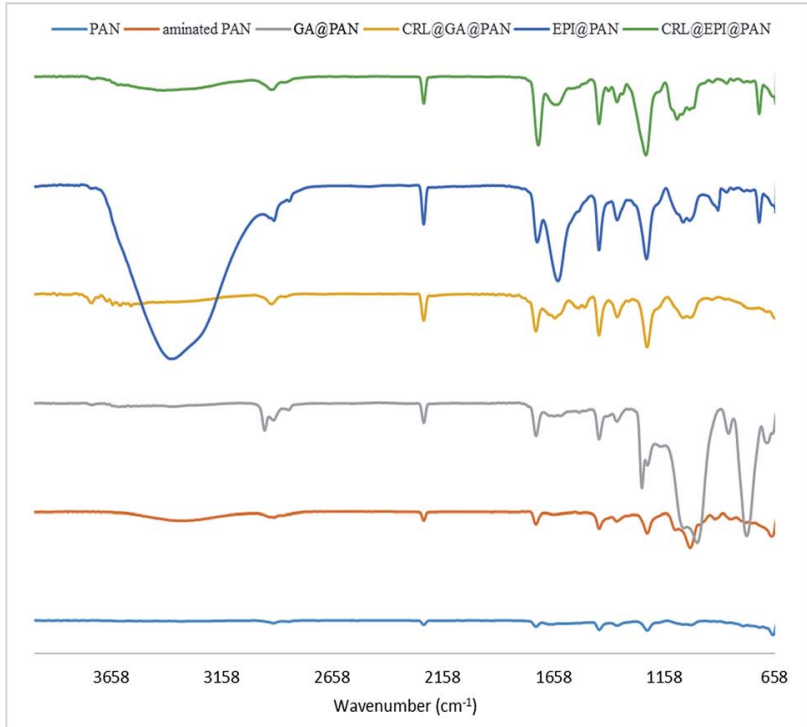

(b)

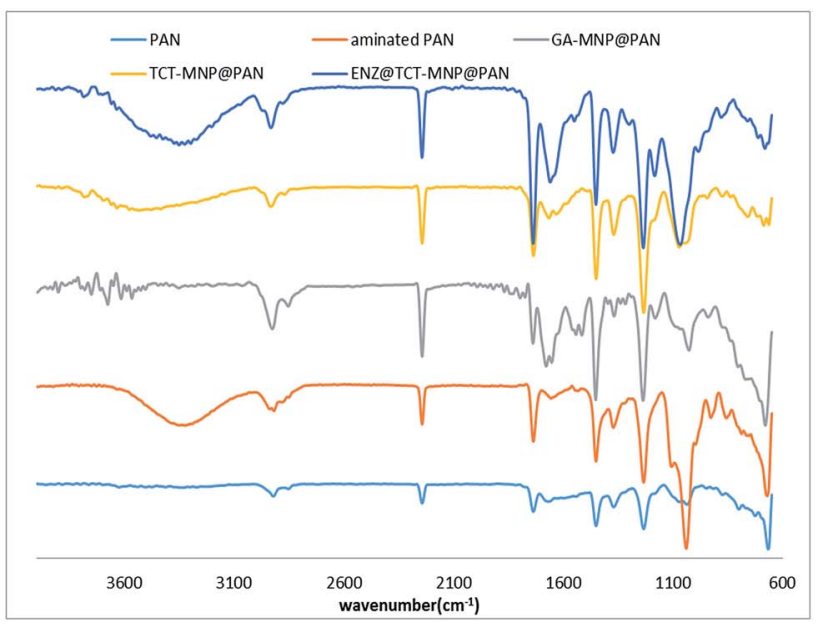

(c)

Fig. 3 ATR spectra of membranes (a) PAN membrane and aminated PAN membrane (b) activated membranes and their enzymatic membranes (c) nanocomposite membranes and their enzymatic membranes. 
represents the $\mathrm{C}-\mathrm{H}$ stretching vibration of GA and APTS on the MNP. In addition, the peak at 1710 in this spectra is referred to the $\mathrm{C}=\mathrm{O}$ stretching bond of aldehyde group. The peaks at 1677 and 1650 represent the bond between aldehyde group to the amine group of the membrane which forms a $\mathrm{C}=\mathrm{N}$ bond. In the spectra of TCT-MNP@PAN, the peak at about 700 corresponds to the $\mathrm{C}-\mathrm{Cl}$ stretching bond of TCT on the MNPs. However, after enzyme immobilization, a broad peak at $3395 \mathrm{~cm}^{-1}$ from stretching $-\mathrm{OH}$ and $-\mathrm{NH}_{2}$ confirmed the presence of the enzyme.

\section{Membrane roughness}

Effect of membrane amination and coating of the membrane with MNPs were investigated by using AFM (Fig. 4). In this study, the average roughness $\left(R_{\mathrm{a}}\right)$ was estimated for a $1 \mu \mathrm{m} \times 1$ $\mu \mathrm{m}, 2 \mu \mathrm{m} \times 2 \mu \mathrm{m}$ and $5 \mu \mathrm{m} \times 5 \mu \mathrm{m}$ surface area of control PAN, aminated PAN membrane, and TCT-MNP@PAN membrane through AFM results. The average roughness of the membranes were presented in Fig. 5(a). The $R_{\mathrm{a}}$ of PAN membrane and aminated PAN membrane were the same in all of the measuring

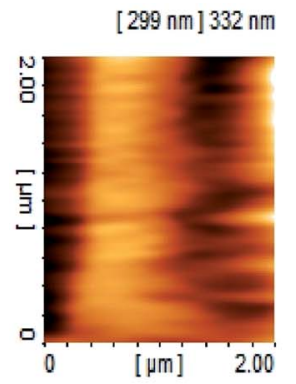

[ $320 \mathrm{~nm}] 336 \mathrm{~nm}$

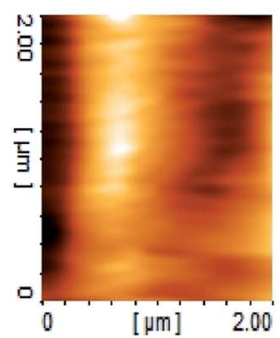

$[464 \mathrm{~nm}] 543 \mathrm{~nm}$

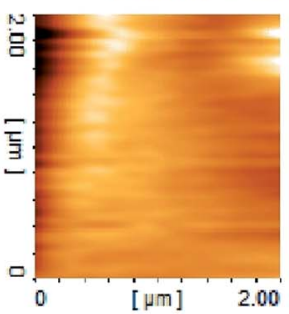

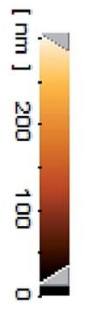

(a)

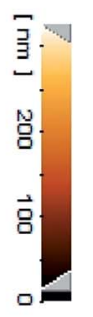

(b)

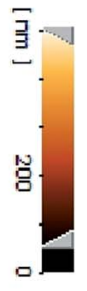

(c)

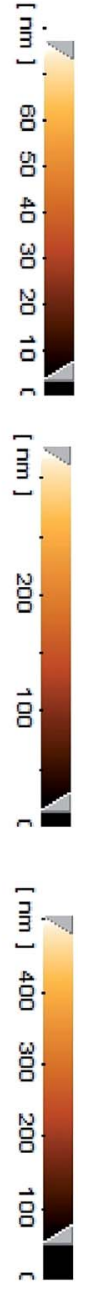

Fig. 4 Three-dimensional AFM topography of membranes and their corresponding roughness images (a) PAN membrane (b) TCTMNP@PAN membrane.

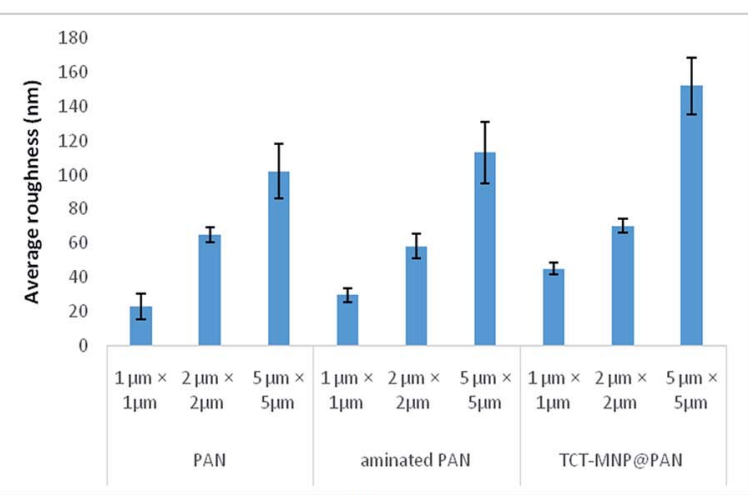

(a)

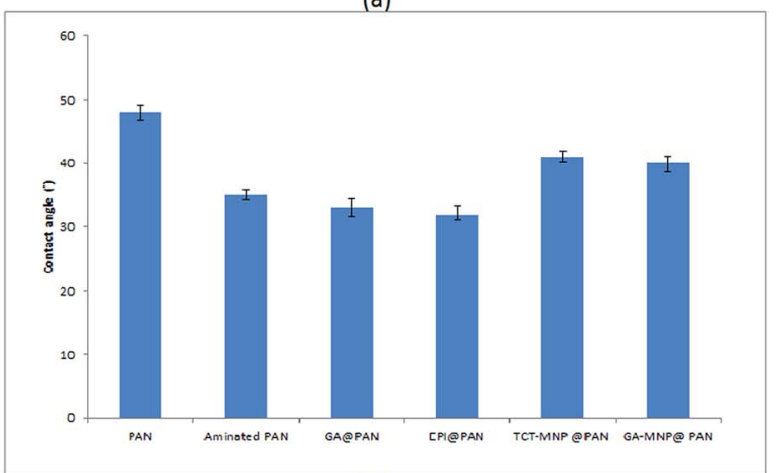

(b)

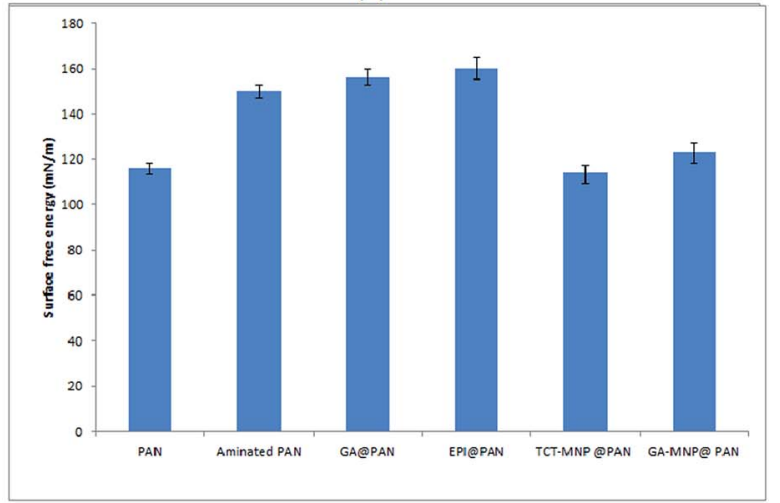

(c)

Fig. 5 (a) Average roughness of PAN membrane, aminated PAN membrane, and TCT-MNP@PAN membrane (b) water contact angle and (c) surface free energy of membranes.

scales. These results show that the chemical reaction only changed the functional groups on the surface of the membrane and did not change the morphology and structure of the membrane. However, the roughness of PAN membrane increased from 22, 65 and $102 \mathrm{~nm}$ to 45,70 and $152 \mathrm{~nm}$ for TCTMNP@PAN membrane in the scale of $1 \mu \mathrm{m} \times 1 \mu \mathrm{m}, 2 \mu \mathrm{m} \times 2$ $\mu \mathrm{m}$ and $5 \mu \mathrm{m} \times 5 \mu \mathrm{m}$, respectively. In our previous study regarding the preparing the nanocomposite membrane by the dip-coating of $\mathrm{Fe}_{3} \mathrm{O}_{4} @ \mathrm{SiO}_{2}$ NPs in the polyethersulfone UF membrane, average roughness decreased after the dipcoating: ${ }^{30}$ It can be concluded that in the dip-coating method, nanoparticles would be trapped in the pores of membrane which causes the reduction in roughness. However, in the presented method, nanoparticles would be placed on the surface of the membrane and causes the increase in roughness. 


\section{Water contact angle and surface energy}

Water contact angle and surface free energy of PAN membrane, aminated PAN membrane, activated membranes, and nanocomposite PAN membranes are presented in Fig. 5(b) and (c). PAN membrane had a water contact angle of about $48^{\circ}$, measured at $5^{\text {th }}$ second after falling drop, respectively. A hydrophilic surface with low water contact angle lets the drop to spread and provides a high surface energy. ${ }^{\mathbf{4 0 , 4 1}}$ The high surface energy of PAN membrane and aminated PAN membrane showed moderate hydrophilic properties of them. Functionalizing the membrane with amine groups decreased the water contact angle and increased the surface energy which showed the hydrophilic properties of the membrane after amination. Activating the membrane with GA or EPI, decreased the contact angle which showed the hydrophilic properties of these membrane which may be due the active functional groups of these molecules. After attaching the nanoparticles to the membrane, surface energy increased and water contact angle decreased. Based on the Wenzel model, roughening the hydrophilic surface (contact angle $<90^{\circ}$ ), transforms it into a superhydrophilic surface. ${ }^{42}$ Here, amination made the PAN membrane more hydrophilic and after increasing the roughness by attaching the nanoparticles to the surface, the hydrophilicity of membrane reduced. Nanocomposite membranes which have a higher average roughness are more hydrophilic than the PAN membrane.

\section{Lipase immobilization}

CRL has been immobilized on PAN membrane with four different modifications. The relative activities and immobilization efficiency of immobilized lipases with same initial lipase concentration of $0.6 \mathrm{mg} \mathrm{mL} \mathrm{m}^{-1}$ are presented in Fig. 6(a). The activities and immobilization efficiency of immobilized lipase on GA and EPI activated PAN membrane was almost same. GA is widely used for enzyme immobilization which provides a heterofunctional supports. $^{31,43}$ GA and EPI links to diaminopropane which has a three chain hydrocarbons and acts as a spacer arm on the membrane. EPI provides epoxy groups on the surface of membrane which has linked to amine groups of diaminopropane. These epoxy-amine groups are active for lipase immobilization via adsorption or covalent linkage that could occur between nucleophilic groups of the enzyme (amino, thiol, and hydroxyl) and the epoxy groups on the membrane surface. ${ }^{44}$ Lipase was immobilized on the membrane via covalent bonding to aldehyde group and epoxy groups of GA and EPI, respectively. ${ }^{\mathbf{4 4}}$

However, these heterofunctional supports have provided two types of immobilization: (i) physical adsorption of lipases (e.g., by ionic exchange, by adsorption on immobilized metal chelates or hydrophobic surfaces); and (ii) covalent immobilization via aldehyde and epoxy groups. ${ }^{31,44}$

In the case of using MNPs, TCT and GA functionalized MNPs were linked to the spacer arms and provided heterofunctional supports for lipase immobilization. According to Fig. 5, NCPAN membranes had higher average roughness and more hydrophobic properties than GA and EPI activated PAN membranes.

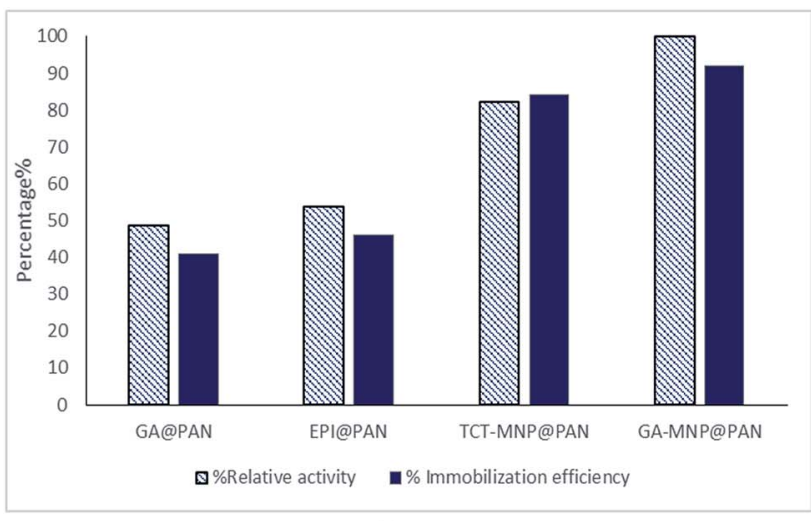

(a)

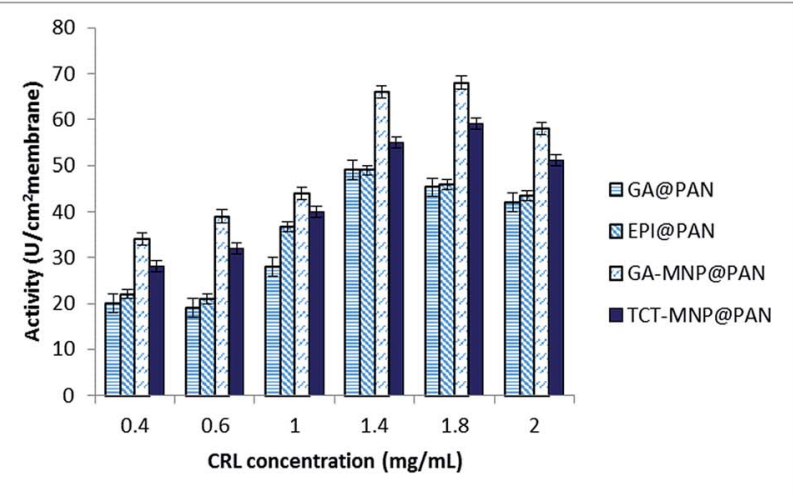

(b)

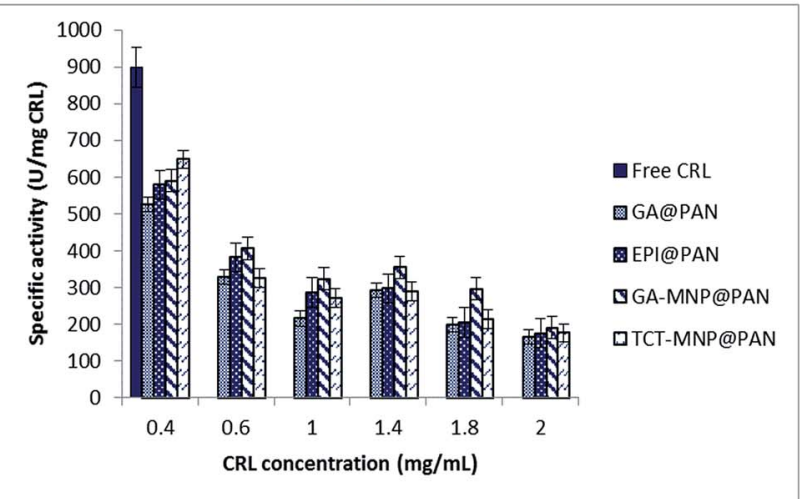

(c)

Fig. 6 (a) Relative activity and loading efficiency of immobilized CRL on different membranes (b) activity of immobilized CRL on membranes at different lipase concentrations (c) specific activity of immobilized CRL on membranes at different lipase concentrations.

These properties have provided more options for lipase immobilization on membrane surface. Thus, it can be seen in Fig. 6(a) that the activity of immobilized lipase on GA and TCT functionalized NCPAN membrane were about $50 \%$ and $31 \%$ higher than that of immobilized on GA-activated PAN membrane. By increasing the CRL concentration, specific activity of immobilized lipases reduced due to high loading of the enzyme. Due to the immobilization, a conformational change in the $3 \mathrm{D}$ structure of enzyme, random attachment of enzyme from different amine residues and mass transfer limitation may be accrued which reduce the activity of the immobilized enzyme in comparison to free enzyme. 
In the case of enzyme immobilization on the membrane, mass transfer limitations reduce the availability of substrate to enzyme. 11,14,45 According to Fig. 6(b) and (c) different enzyme concentrations $\left(0.4-2 \mathrm{mg} \mathrm{mL}{ }^{-1}\right)$ were used for immobilization to optimize the enzyme concentration. The activities of ENZ@GA-MNP@PAN and ENZ@TCT-MNP@PAN were enhanced with the increase of enzyme concentration to $1.8 \mathrm{mg}$ $\mathrm{mL}^{-1}$. However, the specific activity reduced with the increase in enzyme concentration (Fig. 6(b) and (c)). It can be concluded that some enzymes have been overloaded on the membrane and increased the loading capacity. However, according to washing the membranes, the activity has reduced. Here, the activity was in the range of activities of our previous study regarding the lipase immobilization on $\mathrm{Fe}_{3} \mathrm{O}_{4} @ \mathrm{SiO}_{2}$ dip-coated membrane. ${ }^{30}$ It can be concluded that the active site of the enzyme immobilized on GA-MNP@PAN and after that TCT-MNP@PAN membrane is more available than other immobilized enzymes. In addition, the presence of MNPs on the surface of the membrane changed the morphology and chemistry of the surface which helped the enzyme to be attached in proper structure and higher amount than that of membranes which was activated with GA or EPI.

\section{Kinetic parameters}

The kinetic parameters of free lipase and immobilized lipase on the membrane were determined using the Lineweaver-Burk plot and are shown in Table 1 . The $v_{\max }$ shows the highest rate of enzymatic reaction when the enzyme is saturated with the substrate and the $K_{\mathrm{m}}$ value shows the affinity of the enzyme for the substrate. Substrate concentration on the environment of enzyme affect the $K_{\mathrm{m}}{ }^{46}$ The results indicate a reduction in $V_{\max }$ for immobilized lipases in comparison to free lipase which has been observed for CRL immobilized on silica, zirconia and niobium oxide ${ }^{47}$ and nanocomposite membrane. ${ }^{30}$ This may be due to the mass transfer limitation in the case of enzyme immobilization on membranes and has been reported for various supports. ${ }^{48,49}$ However, $V_{\text {max }}$ for immobilized lipase were in the same range which shows that the accessibility of substrate for immobilized enzyme on membrane was limited by the structure of membrane The $K_{\mathrm{m}}$ values for immobilized lipases are lower than the free one, which showed a higher affinity of the substrate for immobilized lipase. This reduction has been perceived for lipase immobilization on magnetic nanoparticles ${ }^{27}$ and membrane. ${ }^{30}$ However, it was observed that $K_{\mathrm{m}}$ value increased from free to immobilized lipase in some studies regarding the immobilization of lipase on membrane

Table 1 Kinetic parameters of free and immobilized lipase

\begin{tabular}{lll}
\hline Sample & $K_{\mathrm{m}}(\mathrm{mM})$ & $v_{\max }\left(\mathrm{U} \mathrm{mg}^{-1}\right)$ \\
\hline Free CRL & 0.213 & 4854 \\
ENZ@GA @PAN & 0.154 & 907.44 \\
ENZ@EPI@PAN & 0.112 & 915.67 \\
ENZ@GA-MNP@PAN & 0.0998 & 950.57 \\
ENZ@TCT-MNP@PAN & 0.0502 & 979.35
\end{tabular}

surface..$^{1,7,45,50}$ It has been reported that immobilization of lipase on surfaces would improve lipase activity by rearranging the conformational structure (termed as 'lid') which opens its active site. ${ }^{12}$ Here, nanocomposite membranes had a lower $K_{\mathrm{m}}$ and higher $V_{\max }$ in comparison to activated membranes. It was observed that the activity and loading efficiency of lipase on nanocomposite membrane was higher than the activated membranes. This may be due to the presence of nanoparticles which supply more available active groups for enzyme immobilization and providing better conformation for lipase due to immobilization on nanoparticles. However, despite the lower activity of ENZ@TCT-MNP@PAN than ENZ@GA-MNP@PAN, immobilized enzyme on TCT-MNP@PAN membrane had a lower $K_{\mathrm{m}}$ and higher $V_{\max }$ which may be due to the better conformational change in the enzyme that leads to a higher possible formation of substrate-enzyme complex and more available active sites.

\section{Effect of hydrophilicity on lipase activity}

It is worth noting that, a moderate hydrophilic membrane is more suitable to supply a contact between substrate and lipase, while hydrophobic surfaces can increase the activity of lipase. ${ }^{\mathbf{1 2}}$ According to Fig. 5(b) and (c), nanocomposite membranes which are more hydrophobic than activated membranes, have showed higher activity. This is in accordance with the results of Chen et $a .^{14}$ which stated that the lipase exhibits a higher activity when the membrane has a higher hydrophobicity. Although, the kinetic parameters have confirmed the better lipase conformation on nanocomposite membranes. In this way according to the hydrophilic properties of activated membranes and nanocomposite membrane, nanocomposite membranes are good candidates for lipase immobilization.

\section{Storage stability of immobilized lipase on TCT-MNP@PAN membrane}

The storage stability of immobilized lipase on TCT-MNP@PAN was examined in the dried and wet condition (Fig. 7). It can be seen that the stability of immobilized enzyme at room

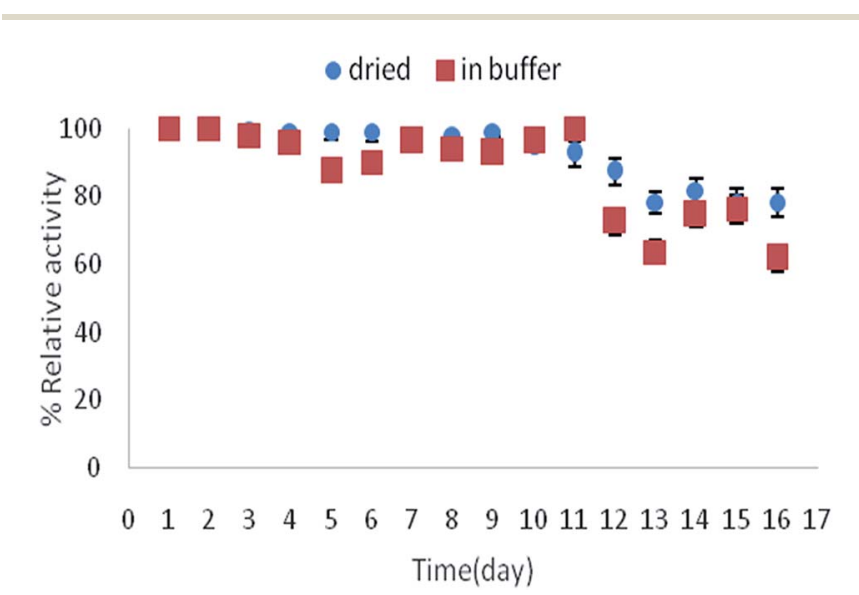

Fig. 7 Storage stability of immobilized lipase on TCT-MNP@PAN at room temperature in buffer or dried state. 
temperature is satisfying. While drying the membrane is more comfortable than drying the nanoparticles, using immobilized enzyme on nanocomposite membranes is more desirable.

\section{Conclusions}

In this work, easy, low cost and practical activated and nanocomposite membranes were prepared to covalently immobilize lipase enzyme. In this regards, PAN membranes were aminated and activated with GA or EPI. In the other method, TCT and GA functionalized magnetic nanoparticles were attached to the aminated PAN membrane and afterwards lipase was immobilized on these membranes. Various techniques such as SEM, TEM, XRD, FTIR, ATR, AFM, contact angle goniometry and surface free energy measurement were applied to characterize the nanoparticles and membranes. According to the relative activity, loading capacity and kinetic parameters of the enzymatic membrane, enzymatic nanocomposite membranes (TCTMNP@PAN and GA-MNP@PAN) were improved in comparison to lipase immobilized on activated membrane (EPI@PAN and GA@PAN). These membranes have been applied for biodiesel production by the authors of this study which will be presented in the further work.

\section{Conflicts of interest}

There are no conflicts to declare.

\section{Acknowledgements}

This work was supported by the research council of the Isfahan University.

\section{Notes and references}

1 P. Ye, Z.-K. Xu, J. Wu, C. Innocent and P. Seta, Macromolecules, 2006, 39, 1041-1045.

2 L. T. Izrael Živković, L. S. Živković, B. M. Babić, M. J. Kokunešoski, B. M. Jokić and I. M. Karadžić, Biochem. Eng. J., 2015, 93, 73-83.

3 M.-M. Zheng, L. Dong, Y. Lu, P.-M. Guo, Q.-C. Deng, W.-L. Li, Y.-Q. Feng and F.-H. Huang, J. Mol. Catal. B: Enzym., 2012, 74, 16-23.

4 M. Aghababaie, M. Beheshti, A. Razmjou and A. K. Bordbar, Biofuel, 2017, 1-7.

5 W. Yujun, X. Jian, L. Guangsheng and D. Youyuan, Bioresour. Technol., 2008, 99, 2299-2303.

6 P. Ye, Z.-K. Xu, J. Wu, C. Innocent and P. Seta, J. Mol. Catal. B: Enzym., 2006, 40, 30-37.

7 S. Gupta, Yogesh, S. SJaviya, M. Bhambi, C. S. Pundir, K. Singh and A. Bhattachary, Int. J. Biol. Macromol., 2008, 42, 145-151.

8 S.-F. Li, Y.-H. Fan, R.-F. Hu and W.-T. Wu, J. Mol. Catal. B: Enzym., 2011, 72, 40-45.

9 P. Ye, J. Jiang and Z.-K. Xu, Colloids Surf., B, 2007, 60, 62-67. 10 R. A. Sheldon, Adv. Synth. Catal., 2007, 349, 1289-1307.
11 P. Ye, Z.-K. Xu, J. Wu, C. Innocent and P. Seta, Biomaterials, 2006, 27, 4169-4176.

12 N. S. Pujari, B. K. Vaidya, S. Bagalkote, S. Ponrathnam and S. Neneb, J. Membr. Sci., 2006, 285, 395-403.

13 N. Hilal, R. Nigmatullin and A. Alpatova, J. Membr. Sci., 2004, 238, 131-141.

14 G.-J. Chen, C.-H. Kuo, C.-I. Chen, C.-C. Yu, C.-J. Shieh and Y.-C. Liu, J. Biosci. Bioeng., 2012, 113, 166-172.

15 G. Vitola, D. Büning, J. Schumacher, R. Mazzei, L. Giorno and M. Ulbricht, Macromol. Biosci., 2017, 17, 1600381.

16 X. Zhao, Y. Su, W. Chen, J. Peng and Z. Jiang, J. Membr. Sci., 2012, 415-416, 824-834.

17 J. Hou, G. Dong, Y. Ye and V. Chen, J. Membr. Sci., 2014, 469, 19-30.

18 P. Daraei, S. S. Madaeni, N. Ghaemi, E. Salehi, M. A. Khadivi, R. Moradian and B. Astinchap, J. Membr. Sci., 2012, 415-416, 250-259.

19 P. Jian, H. Yahui, W. Yang and L. Linlin, J. Membr. Sci., 2006, 284, 9-16.

20 Z.-Q. Huang, F. Zheng, Z. Zhang, H.-T. Xu and K.-M. Zhou, Desalination, 2012, 292, 64-72.

21 A. Razmjou, J. Mansouri and V. Chen, J. Membr. Sci., 2011, 378, 73-84.

22 L. Yan, Y. S. Li, C. B. Xiang and S. Xianda, J. Membr. Sci., 2006, 276, 162-167.

23 L.-Y. Yu, Z.-L. Xu, H.-M. Shen and H. Yang, J. Membr. Sci., 2009, 337, 257-265.

24 J. S. Taurozzi, H. Arul, V. Z. Bosak, A. F. Burban, T. C. Voice, M. L. Bruening and V. V. Tarabara, J. Membr. Sci., 2008, 325, 58-68.

25 Y. Orooji, M. Faghih, A. Razmjou, J. Hou, P. Moazzam, N. Emami, M. Aghababaie, F. Nourisfa, V. Chen and W. Jin, Carbon, 2017, 111, 689-704.

26 M. L. Verma, C. J. Barrow and M. Puri, Appl. Microbiol. Biotechnol., 2013, 97, 23-39.

27 E. Ranjbakhsh, A. K. Bordbar, M. Abbasi, A. R. Khosropour and E. Shams, Chem. Eng. J., 2012, 179, 272-276.

28 Y. Cui, Y. Li, Y. Yang, X. Liu, L. Lei, L. Zhou and F. Pan, J. Biotechnol., 2010, 150, 171-174.

29 S. Kanimozhi and K. Perinbam, Mater. Res. Bull., 2013, 48, 1830-1836.

30 M. Aghababaie, M. Beheshti, A. Razmjou and A.-K. Bordbar, Food Bioprod. Process., 2016, 100, 351-360.

31 O. Barbosa, R. Torres, C. Ortiz, Á. Berenguer-Murcia, R. C. Rodrigues and R. Fernandez-Lafuente, Biomacromolecules, 2013, 14, 2433-2462.

32 X.-J. Huang, P.-C. Chen, F. Huang, Y. Ou, M.-R. Chen and Z.-K. Xu, J. Mol. Catal. B: Enzym., 2011, 70, 95-100.

33 C.-C. Lin and M.-C. Yang, Biomaterials, 2003, 24, 549-557.

34 C. J. Van Oss, L. Ju, M. K. Chaudhury and R. J. Good, J. Colloid Interface Sci., 1989, 128, 313-319.

35 M. M. Bradford, Anal. Biochem., 1976, 72, 248-254.

36 G. E. P. Box and K. B. Wilson, J. Roy. Stat. Soc. B, 1951, 13, $1-45$.

37 Y.-T. Zhu, X.-Y. Ren, Y.-M. Liu, Y. Wei, L.-S. Qing and X. Liao, Mater. Sci. Eng., C, 2014, 38, 278-285. 
38 A. K. Bordbar, A. A. Rastegari, R. Amiri, E. Ranjbakhsh, M. Abbasi and A. R. Khosropour, Biotechnol. Res. Int., 2014, 2014, 6 .

39 M. Mihailović, M. Stojanović, K. Banjanac, M. Carević, N. Prlainović, N. Milosavić and D. Bezbradica, Process Biochem., 2014, 49, 637-646.

40 Z. Xu, J. Wang, L. Shen, D. Men and Y. Xu, J. Membr. Sci., 2002, 196, 221-229.

41 J. Wang, G. Meng, K. Tao, M. Feng, X. Zhao, Z. Li, H. Xu, D. Xia and J. R. Lu, PLoS One, 2012, 7, e43478.

42 R. N. Wenzel, Ind. Eng. Chem., 1936, 28, 988-994.

43 O. Barbosa, C. Ortiz, A. Berenguer-Murcia, R. Torres, R. C. Rodrigues and R. Fernandez-Lafuente, RSC Adv., 2014, 4, 1583-1600.

44 C. Mateo, R. Torres, G. Fernández-Lorente, C. Ortiz, M. Fuentes, A. Hidalgo, F. López-Gallego, O. Abian,
J. M. Palomo, L. Betancor, B. C. C. Pessela, J. M. Guisan and R. Fernández-Lafuente, Biomacromolecules, 2003, 4, 772-777.

45 P. Ye, Z.-K. Xu, J. Wu, C. Innocent and P. Seta, J. Mol. Catal. B: Enzym., 2006, 40, 30-37.

46 R. C. Rodrigues, C. Ortiz, A. Berenguer-Murcia, R. Torres and R. Fernandez-Lafuente, Chem. Soc. Rev., 2013, 42, 6290-6307. 47 L. T. Izrael Živković, L. S. Živković, B. M. Babić, M. J. Kokunešoski, B. M. Jokić and I. M. Karadžić, Biochem. Eng. J., 2015, 93, 73-83.

48 M. Kalantari, M. Kazemeini, F. Tabandeh and A. Arpanaei, J. Mater. Chem., 2012, 22, 8385-8393.

49 C. J. van Oss, M. K. Chaudhury and R. J. Good, Adv. Colloid Interface Sci., 1987, 28, 35-64.

50 S.-H. Chiou and W.-T. Wu, Biomaterials, 2004, 25, 197-204. 